\title{
REPONER, REPENSAR, REVIVIR ${ }^{1}$
}

\author{
Re-plenish, Re-think, Re-live
}

\author{
DIAMELA ELTIT \\ Escritora
}

DOI: https://doi.org/10.5565/rev/mitologias.832

vol. 24 | noviembre 2021 | 87-93

Quiero saludar de manera muy especial a cada una de las organizadoras del seminario "Bordeando Fronteras. Seminario sobre narradoras latinoamericanas" que realiza la Cátedra Extraordinaria Carlos Fuentes de Literatura Hispanoamericana de la UNAM (Universidad Nacional Autónoma de México), junto con Cultura y Libros UNAM y la Universidad Complutense de Madrid y la Universidad de Costa Rica. Dejar un cariñoso saludo a mis queridas amigas Alexandra Saavedra y Karla Morales. Destacar la intervención de la Doctora Evangelina Soltero. Y especialmente relevar el trabajo de Socorro Venegas y Juan Casamayor por la edición del libro Vindictas. Cuentistas latinoamericanas (Páginas de Espuma, 2021). ${ }^{2}$ Saludar también a cada uno de las y los participantes. Agradezco la invitación a participar en la sesión de cierre de este importante evento y me permitiré compartir, aquí, con ustedes, siempre de manera incierta, provisional, ciertas preguntas críticas o flujos de pensamientos que me rondan relacionadas con el alucinante oficio de escribir.

En un determinado registro analítico o, quizás, desde una perspectiva extremadamente hipotética, se puede pensar en el tiempo como una ficción. Porque después de todo, más allá de la ciencia, de la relación tiempo-espacio o de la resonante teoría de la relatividad, su segmentación responde a una codificación cultural y arbitraria donde se insertan telones y entretelones en los que ocurren y transcurren los sucesos.

El dilema del tiempo atraviesa la totalidad de la historia cultural, desde el mito a la ciencia, opera como hecho primordial para cada uno de los pueblos, funciona como una incógnita permanente que

\footnotetext{
${ }^{1}$ [Nota de los Eds.] El presente ensayo corresponde a la conferencia magistral dada por Diamela Eltit, con la que se cerró con broche de oro el Seminario "Vindictas Bordeando Fronteras", organizado por la Universidad Nacional Autónoma de México y la Universidad Complutense de Madrid. El ensayo también será publicado en la colección Cuadernos Cátedras de la UNAM y podrá descargarse en: http://www.cuadernoscatedras.unam.mx/. Asimismo, la conferencia puede verse en el siguiente enlace: https://www.youtube.com/watch?v=XLYJX5W-37g.

2 [Nota de los Eds.] El libro Vindictas forma parte del proyecto editorial "Vindictas" del sello Libros UNAM, dirigida por la escritora Socorro Venegas, el cual busca hacer visible la obra de autoras latinoamericanas del siglo pasado, que debido a una visión machista de la literatura no tuvieron difusión. Para más información véase: http://vindictas.unam.mx/sitio/vindictas.
} 
requiere de la búsqueda de una verdad o de verdades para entender y especialmente entenderse en su devenir, en su sobrevivencia, en la muerte.

El pensamiento científico ha trabajado de manera incesante para encontrar una respuesta mediante la sofisticada abstracción de sus supuestos. La ciencia espectaculariza cada una de sus teorías, volcadas a promover lo comprobable. Sin embargo, las certezas son relativizadas ante nuevas aristas científicas o bien por renovadas teorías que piensan y repiensan el tiempo en sus tiempos.

Entre otras posiciones teóricas actuales, quiero recordar aquí al físico Julián Barbour, profesor de la Universidad de Oxford, que en su libro El final del tiempo [The End of Time: The Next Revolution in our Understanding of the Universe, 1999] asegura en una entrevista en torno a su libro, que el tiempo es una ilusión. Dice:

Mi idea básica es que el tiempo como tal no existe... pero hay cosas que se pueden llamar instantes de tiempo o 'ahoras'... me propongo salir de todo lo que no se pueda ver... para mantener la idea de que son muchas cosas diferentes que coexisten a la vez, en una conexión mutua. Hay muchos de los ahoras, todos diferentes los unos de los otros. Esa es mi ontología del universo. Hay ahoras, nada más ni nada menos.

Su propuesta audaz y posible abre un nuevo tiempo para este preciso tiempo o este ahora o más bien "ahoras", como diría Barbour.

$\mathrm{Y}$, desde otro lugar, cercano al que hoy nos convoca, en un recuento cronológico, plenamente cultural, recuerdo al prestigioso historiador marxista inglés, Eric Hobsbawm, quien se refirió al siglo XX como un siglo corto. Definió como su inicio la gran guerra en la medida que consideró los primeros 14 años todavía no despegados de los paradigmas del siglo XIX y señaló que el siglo terminó con la caída de la Unión Soviética. El historiador analizó ese siglo corto como un tiempo marcado por la destrucción. O, en palabras del filósofo Isaiah Berlín: "He vivido durante la gran parte del siglo XX sin haber experimentado — debo decirlo— sufrimientos personales. Lo recuerdo como el siglo más terrible de la historia de Occidente".

Y es así, un siglo terrible porque las dos guerras mundiales dejaron 187 millones de personas muertas. El siglo XX fue un siglo devastador e innovador a la vez. Corto para uno de los historiadores contemporáneos más importantes del siglo, interminable para las y los ciudadanos que experimentaron esas guerras. Un siglo productivo para la ciencia y la tecnología, acelerado para las comunicaciones, veloz para la proliferación de imágenes, proclive para la pregunta acerca de las identidades, pensante ante las emancipaciones.

Pero el siglo o los siglos permiten pensar relacionalmente tiempo y cuerpo. Lenguaje, tiempo y cuerpo. En el interior de esa ficción posible, en su más plena y decisiva cronología, el siglo XX, sus cien años han terminado y en otro vértice se encadenan con siglos anteriores que no dejan de ocurrir en el complejo entramado de las repeticiones signadas por los poderes, las dominaciones y las siempre incesantes guerras. El siglo XX se replica en el XXI a su manera, conserva intactas las dominaciones y esa ferocidad armamentista tan conocida. Persiste de manera masiva la opresión sobre los oprimidos.

Pero la grandeza de algunos ahoras, como diría Barbour, no es ajena a los avatares del siglo. Y ante un ahora sorprendente quiero recordar aquí uno de los hitos literarios que quebró una forma monótona de valoración literaria a mediados del siglo XX. Me refiero a la obtención del Premio Nobel para la poeta y ensayista chilena Gabriela Mistral (Vicuña, 1889-Nueva York, 1957) el año 1945. En ese tiempo, ese premio constituía una verdad cultural incuestionable y tenía una resonancia extraordinaria o extrema no solo para la persona premiada sino para la totalidad del país. Y, desde luego, fue absolutamente inesperado que el primer Nobel latinoamericano le fuera otorgado a una mujer. Pero, "el 
caso Mistral" siempre fue inusual y en cierto modo asombroso. Nació en el llamado "Norte chico" chileno. Su padre abandonó a su madre cuando la poeta tenía tres años y su media hermana fue la encargada de alfabetizarla. Lo realmente curioso fue que la escritora nunca asistió a ningún establecimiento educacional, ella consiguió su certificación como profesora de enseñanza básica mediante una serie de complejas estrategias operando como ayudante de profesora en colegios ubicados en pueblos alejados de las ciudades. Lo hizo en los momentos en que era fundamental alfabetizar y así finalmente, debido a este trabajo como asistente de profesoras, consiguió su certificación como maestra de enseñanza primaria.

Pero su gran capacidad intelectual, su pasión por la lectura, la llevó en su adolescencia a escribir artículos en periódicos y más adelante a escribir poesía, lo que le posibilitó abrir vínculos con los intelectuales y escritores de su tiempo. Más adelante, por sus méritos literarios, la Universidad de Chile, la más importante del país, le otorgó, por gracia, el título universitario de profesora, lo que hizo posible que fuera nombrada Directora de un liceo estatal, lo que constituía para su tiempo un cargo de máxima relevancia.

Así, sin concurrir nunca a las aulas obtuvo su título universitario. Mientras era Directora de liceo, en 1922, el Ministro de Educación mexicano, José Vasconcelos, bajo la presidencia de Álvaro Obregón, la invitó a participar de la reforma educacional mexicana y formó parte de las llamadas "misiones culturales" destinadas a habilitar profesores para alfabetizar a la población.

Durante los años 30 fue profesora invitada en el Barnard College y el en el Vassar College, en Estados Unidos, ambos espacios de un gran prestigio social y académico y más adelante ocupó cargos diplomáticos. Lo que me interesa señalar aquí, es que, desde una emergencia periférica, ajena a los centros, con una formación autodidacta en el sentido más radical del término, la escritora consiguió construir un espacio cultural de una magnitud inesperada, considerando el lugar subsidiario asignado a las escritoras para ese nivel de reconocimiento literario.

La obtención del Premio Nobel produjo admiración y desencadenó también descontento en escritores permeados por estructuras fundamentalmente machistas. La poesía de Gabriela Mistral es compleja, decisiva, audaz, intensa. Ahora mismo es así y lo seguirá siendo en los siglos venideros:

Me alejaré cantando mis venganzas hermosas porque hasta ese hondor recóndito la mano de ninguna bajará a disputarme tu puñado de huesos. (vv. 12-14, "Los sonetos de la muerte")

Las autoridades chilenas, y la ciudadanía, celebró con orgullo el premio. Sin embargo, en el post premio, el Estado construyó la figura de Gabriela Mistral como una madre nacional, promovió con énfasis una función poética materna mediante la exaltación de su trabajo como profesora y la extrema promoción de rondas infantiles. Mistral no tuvo hijos. Su soltería fue adjudicada a un amor interminable por un suicida hacia el que, aseguraban los relatos oficiales, mantuvo una especie de fidelidad "eterna". Se construyó, así, una historia mítica que fue incorporada a los programas educacionales, incluyendo de manera primordial el relato del amor imposible. A pesar de que en el ámbito específico literario circulaba la versión de que la escritora era lesbiana, esa identidad parecía imposible de aceptar y las tímidas versiones que insinuaban dudas acerca de sus preferencias amorosas eran duramente desmentidas y tachadas de calumnias por los llamados "mistralianos".

Recién en el siglo XXI, después de que el gobierno de Chile adquirió la parte de su archivo que había pertenecido a Doris Dana, su joven amante, su última compañera, entre otros documentos, estaban las cartas de amor de la poeta. Su lesbianismo se hizo público. Las cartas fueron publicadas con 
la cooperación estatal y solo en este tiempo, en este siglo, fue posible aceptar la preferencia sexual de la escritora. ${ }^{3}$

Y en este mismo siglo, los movimientos feministas han recuperado la imagen de Gabriela Mistral, ya no como símbolo de maternidad y protagonista de amores imposibles, sino como un ícono de representación cultural en el interior de espacios emancipadores. Pero, la excepción Mistral, en el siglo XX fue transformada en norma en la medida que sobre ella se dejaron caer estereotipos de género que operaron de manera masiva con una gran efectividad. Y fueron esas escrituras sociales de lo femenino, las que la relegaron desde lo público al espacio privado al designarla ya no como productora de letra sino como reproductora, y fue signada filiada a un tipo de maternidad poética y su pesar eterno por un amor desdichado.

Su condición de escritora y ensayista se redujo, al establecer una aguda y decisiva unión entre biología y género, y de esa manera la pluralidad y la fuerza de su letra fue segregada al territorio de un tipo del melodrama y a un conjunto de estereotipos completamente cursis. Así, a la obra de la primera y única Nobel latinoamericana fue impregnada de categorías "femeninas" que afectaron la recepción y difusión de su trabajo.

El libro Vindictas, editado por Socorro Venegas y Juan Casamayor, cuyo título alude tanto a venganza como a reparación, establece una geografía de la letra, traza un mundo, es un decir, escrito a la manera de un mapa que busca establecer marcas mediante relatos que emanan de territorios. Juan Casamayor asegura que "una antología es una historia de ausencias" lo que es completamente acertado. El diálogo entre el filólogo y editor con Socorro Venegas apunta a la naturalización de la escritura como un tipo de épica que le pertenece a los hombres y donde las mujeres son una indiscutible minoría o bien pertenecen a otro mundo, a una subespecie literaria.

Son frecuentes o muy frecuentes las disputas entre escritores conocidos, sus desacuerdos en parte se transforman en leyendas, en causas guerreras, precisamente por la estela épica que se les adjudica. El "caso Mistral" que mencioné muestra cómo la ocupación de un gran lugar cultural literario no garantiza que esa letra no sea intervenida por construcciones emanadas de controles discursivos generados por categorías binarias, que impiden que habite el mismo espacio que las letras emanadas de sus otros.

Desde luego Vindictas es un libro indispensable que permite indagar en producciones de autoras atrapadas doblemente: entre sus fronteras geográficas y la frontera impuesta por el género. Parece necesario señalar que aun en este tiempo central para las comunicaciones instantáneas, la circulación de libros continúa, de manera general, limitada. Las editoriales independientes difícilmente se desplazan más allá de sus propios territorios, y eso genera un no saber aun entre países vecinos y, desde luego, ese no saber se hace más intenso para las autoras.

Quisiera evocar aquí un momento muy clave como fue la creación y consolidación entre literatura latinoamericana y mercado. Precisamente el llamado "boom" abrió un espacio inédito para el continente, un boom generado a partir de escritores jóvenes, poseedores de indudables y sólidos méritos literarios, quienes, desde España ingresaron a un campo inédito para esas literaturas: autores mediados por agentes literarios, presencias en suplementos culturales, conferencias, traducciones. Ellos se transformaron así en la literatura latinoamericana. Desde luego el campo literario ya estaba poblado por numerosos escritores y de escritoras muy influyentes en los ámbitos, digamos, letrados. Autores y

\footnotetext{
${ }^{3}$ [Nota de los Eds.] Véanse los epistolarios Niña errante. Cartas a Doris Dana, con prólogo de Pedro Pablo Zegers B., publicado por la editorial Lumen el 2009 y Doris, vida mía, con prólogo de Alia Trabuco, publicado por la editorial Lumen el 2021.
} 
autoras emanados desde sus espacios locales, pero que, lideraban el canon latinoamericano. Pienso en Jorge Luis Borges, Juan Rulfo o Rosario Castellanos.

Pero el boom fue asumido directamente al mercado editorial y los autores participantes se transformaron en referentes culturales y literarios que atravesaron velozmente las fronteras. Desde luego ese boom coincidió con rotundos momentos emancipatorios latinoamericanos que buscaban descolonizar sus materias primas. Desde la literatura las grandes editoriales y sus programas colaboraron en la difusión de las obras hasta volverlas masivas. De una u otra manera se podría decir que el boom profesionalizó a los escritores, convirtió la literatura en una "carrera" y, en cierto modo, la burocratizó en la medida que abrió metas, espacios, condiciones. Unió escritura y gestión, cuerpo y libro, agencia y famas.

Pero, de manera ejemplar y necesariamente inolvidable, el boom no contó en su conformación con ninguna escritora. Más allá de los grandes méritos ya señalados para cada uno de los autores de ese momento, hay que entender el boom también como una "producción" literaria, una selección, un mapa posible, una síntesis literaria de una Latinoamérica que carecía de escritoras. Resulta interesante o importante recordar ese momento, para entender producciones de sentido controladas y dictaminadas por la hegemonía cultural unida a los dictámenes del mercado.

Ya sabemos que Occidente funciona desde una concepción del mundo de orden binaria. Sabemos también que el binarismo de manera inevitable es asimétrico y que es el gran dispositivo político que constituye la matriz de dominación superioridad/inferioridad. En la ecuación hombremasculino y mujer-femenina descansa una de las zonas de dominación más sostenidas y asombrosas a lo largo de la historia. Una dominación que redobla el asombro en la medida que sabemos que las mujeres somos prácticamente la mitad de los habitantes del mundo. Esta fuerza discriminadora en todos y cada uno de los órdenes de los transcursos vitales es posible por la colonización de los imaginarios de las propias mujeres por sentidos que les son adversos y la gran tarea del feminismo, o de los feminismos, es descolonizar, tal como lo expresó de manera intensa Franz Fanon en su libro Los condenados de la tierra (1961).

Desde luego el feminismo o los feminismos como signos emancipadores tienen una larga historia, solo que esa historia ha sido desplazada hacia lugares opacos, laterales, no forman parte de la gran historia y están fuera de los programas de aprendizaje. Así, cada época de irrupción feminista parece inaugural y siempre se abre un nuevo comienzo o se vive lo que se podría denominar como un eterno presente. Pero sus luchas políticas no han cesado. El universo literario, al igual que el resto del aparato social, ha buscado disminuir las brechas e iniciativas como "Vindictas" apuntan en esa dirección. Y eso es importante, necesario. En ese sentido no puedo sino felicitar la iniciativa.

Tengo que señalar aquí, que lo que me moviliza como habitante de las letras desde el siglo XX al XXI, es la democratización literaria. El año 1987 generamos un grupo de seis escritoras, la organización del primer congreso de literatura de mujeres en Chile y uno de los primeros en Latinoamérica. ${ }^{4}$ Una experiencia agotadora por lo iniciática, pero apasionante. Fue el congreso internacional más numeroso e importante realizado bajo dictadura. Pensé entonces, hace casi treinta y cinco años atrás, con un entusiasmo y una ingenuidad que hoy prefiero olvidar, que después de ese congreso iban a cambiar las relaciones literarias. Muy pronto entendí que el sistema operaba rápida y eficazmente. El movimiento que pretendía visibilizar a las autoras se incorporaba de una manera muy compleja al binarismo, pues por una parte se relevaba la producción, pero, simultáneamente se la

\footnotetext{
${ }^{4}$ [Notas de los Eds.] El Primer Congreso Internacional de Literatura Femenina Latinoamericana se inauguró en agosto de 1987. En él intervinieron intelectuales latinoamericanas, entre ellas: Diamela Eltit, Lucía Guerra, Eliana Ortega, Raquel Olea, Ida Vitale, Nelly Richard, Beatriz Sarlo, Sonia Montecino y Soledad Bianchi, entre otras. Las ponencias presentadas se recopilaron en el libro Escribir en los bordes: Congreso Internacional de Literatura Femenina Latinoamericana 1987 (Cuarto Propio, 1990).
} 
segregaba, pues se instalaba el concepto "literatura de mujeres" y, en otro lugar, la literatura. Y en esa operación clasificatoria, la literatura, quizás la verdadera y la única, permanecía filiada al hombre y eso incluía a sus propias disidencias.

Voy a señalar, como lo he hecho en oportunidades anteriores, que existen numerosos y constantes congresos de literatura de mujeres y pese al riesgo de acudir a un ejemplo tosco, no he sabido, hasta ahora, que se realice un congreso de literatura de hombres, con ese exacto título, y eso sucede porque sencillamente no es necesario.

Así, la llamada literatura de mujeres amplía el guetto, como lo menciona Socorro Venegas, aunque, desde luego, se posibilita una mayor visibilidad. La idea que quiero compartir con ustedes es que me parece necesario democratizar el campo literario y para que ocurra es imprescindible desbiologizar la letra, sustraerla de genitalidades y de condicionantes de género e ingresar a la escritura. Pensar la escritura de acuerdo con su eficacia, a sus formas estéticas, a la propuesta poética que porta. Esa me parece una manera de eludir el binarismo, repito la desbiologización de la letra y promover campos literarios de coexistencia, donde la autoría ingrese como mero dato, pero no como centro clasificatorio.

La teórica estadounidense Judith Butler apostó a la proliferación de géneros para romper el binarismo masculino/femenino, su propuesta y su trabajo crítico ha sido un referente indudable. En ese sentido, extrapolando, jugando con los nombres, quisiera apuntar a que la literatura está conformada por una diversidad de géneros, no es binaria, al revés a lo largo de su historia los géneros literarios se han expandido, confundido, mezclados. Discutidos. Han asombrado. Por eso me parece fundamental detenernos en la escritura y sus posibilidades, atender a los lenguajes y sus mutaciones, pensar y repensar la letra.

Entiendo que mi planteamiento pueda portar elementos utópicos, pero, pienso la democratización literaria como un horizonte en construcción que apunta a concentrarse en la pluralidad de la letra, en su diversidad genérica, en la energía de sus ímpetus constructivos.

Hoy mismo atravesamos por un nuevo momento feminista pleno de fuerzas emancipadoras. Resulta importante entender que lo que se entiende por feminismo no es homogéneo, que es un campo cultural y político siempre en disputa, un campo que en su interior porta diferencias y numerosas divergencias. Y eso a mí me resulta valioso pues amplía su alcance y diversifica los modos de incidir. Pero hay que considerar que en este tiempo vivimos un tiempo regido por el mercado híper intensificado y su insaciable ímpetu neoliberal. El mercado neoliberal se apodera de los dilemas y los objetualiza hasta petrificarlos. Los vuelve meramente cosméticos y de rápido consumo. En ese sentido no se puede obviar que este mercado también recae, o cae, sobre el consumo literario en la medida que más que generar un nuevo "boom", esta vez, de mujeres. Pienso que esa construcción más bien busca convertir el largo proceso emancipador en moda y que como toda moda dura apenas una temporada que debe ser renovada cada año o cada día.

En este preciso momento la escritura de mujeres impulsada bajo ese sello - literatura de mujeres - es objeto de fuertes operaciones de mercado. Eso resulta evidente y en un sentido puede transformarse en parodia. Esa parodia ocurrió recientemente en España donde un equipo de hombres ganó un premio literario estruendosamente contundente bajo la firma de mujer. Y más aún, se descubrió que ese grupo, que se define a sí mismo como una sociedad (yo añadiría híper capitalista), era autor de reconocidos bestsellers que operaban con el nombre de Carmen Mola, y ya habían publicado con anterioridad novelas y habían vendido 400.000 ejemplares en un tiempo coincidente con la reciente 
apertura mundializada del feminismo. ${ }^{5}$ A diferencia de importantes escritoras que adoptaron seudónimos masculinos para darle existencia a sus letras, este grupo perfectamente sincronizado y experto en leer y deconstruir los requerimientos del mercado, lo hizo para ganar dinero mediante una impostura y la oferta frívola del neoliberalismo. Digo para ganar un mercado que entiende que la mujer, es un decir, ahora vende. En ese sentido esta situación se enmarca en el mercado y su histórica apropiación múltiple de los dilemas sociales más ardientes. Y, en este caso específico, la apropiación de identidades "de moda".

Desde luego, horadar los efectos del binarismo hombre/mujer asociado a sus respectivas categorías culturales es una tarea que hoy mismo parece imposible o demasiado distante. Quiero repetir aquí, algo que ya he expresado como es la diferencia salarial. En todo el mundo occidental a un mismo trabajo las mujeres ganamos menos que los hombres. Pero para que esto ocurra, significa que se nos paga menos porque para el sistema "valemos" menos. Pienso que es necesario entender de manera lúcida que en ese binarismo, elaborado por la construcción hegemónica, descansa lo medular de la discriminación y la violencia. Pero tenemos que seguir pensando, escribiendo y trazando un horizonte.

Socorro Venegas y Juan Casamayor, los dos juntos, paritarios, inteligentes, realizaron un proyecto que permanecerá como signo, como geografía. Y, espero que, cuando sea posible, ellos se reúnan nuevamente para realizar esa antología igualitaria fundada no en procedimientos aritméticos 50 y 50, o en la pedagógica ley de cuotas - lo enfatizo porque en el caso de las escritoras no es necesario-, sino permitir el despliegue del poder de la letra y su efecto en la multiplicidad de géneros literarios que compartimos y que podemos seguir construyendo.

¿En cuál siglo Socorro Venegas y Juan Casamayor consolidarán esa antología? No lo sé.

En algunos de los ahoras de los ahoras.

Muchas gracias

\footnotetext{
5 [Nota de los Eds.] La autora hace referencia al $70^{\circ}$ Premio Planeta, otorgado en octubre de 2021, dotado por primera vez con un millón de euros (el premio literario más alto del mundo), que fue concedido a la novela La bestia, firmado bajo el pseudónimo de Carmen Mola, y que durante la premiación desveló su identidad resultando ser tres hombres: Jorge Díaz, Agustín Martínez y Antonio Mercero. A la fecha, Carmen Mola ha publicado las obras La novia gitana (2018), La red púrpura (2019) y La Nena (2020).
} 